\title{
Effects of Reverse Bud-grafting on Growth and Nutrient Uptake of Rubber Mini-seedling Buddings
}

\author{
Chen Xianhong, Chen Qing, Wang Jun, Lin Weifu*
}

Rubber Research Institute, Chinese Academy of Tropical Agricultural Sciences, Danzhou, Hainan 571737, China

* Corresponding author

\begin{abstract}
Reverse bud-grafting was used for dwarf production. Dwarf of rubber tree could be against wind damage. To investigate the effects of reverse bud-grafting on rubber trees, the elite planting material mini-seedling budding was used to observe the growth and nutrient uptake. The results showed that compared with conventional cis bud-grafting, at nursery stage, reverse bud-grafting had $16.37 \%$ more $(p<0.05)$ in leaf whorls, $66.66 \%$ more $(p<0.001)$ in rootstock-scion angle, and the diameter of reverse bud-grafting was $23.57 \%$ more $(p<0.01)$ in rootstock, $18.31 \%$ more $(p<0.05)$ in rootstock-scion, and $18.31 \%$ more $(p<0.05)$ in scion, respectively. However, at field stage, the diameter of reverse bud-grafting was $23.25 \%$ less $(p<0.001)$ at 3 months, and $11.65 \%$ less ( $p<0.001)$ at 18 months, than those of cis budgrafting, respectively. Nutrient uptake might account for growth differences. For scion shoot, reverse budgrafting was $34.19 \%$ less $(p<0.001)$ in $N, 16.12 \%$ less $(p<0.01)$ in $P$, and $37.63 \%$ more $(p<0.01)$ in C/N, respectively. For rootstock-scion combination, reverse bud-grafting was $10.76 \%$ less $(p<0.01)$ in $N$, $14.05 \%$ less $(p<0.05)$ in $P, 19.92 \%$ more $(p<0.01)$ in $K, 30.03 \%$ more $(p<0.001)$ in soluble sugar, and $45.94 \%$ more $(p<0.001)$ in $C / N$, respectively. For rootstock, reverse bud-grafting was $39.65 \%$ less $(p<0.001)$ in $N, 38.11 \%$ less $(p<0.001)$ in $P, 5.65 \%$ less $(p<0.05)$ in $K$, and $67.31 \%$ more $(p<0.001)$ in $C / N$, respectively. Taken together, bigger diameter of rootstock-scion combination caused by reverse budgrafting, affected the growth of mini-seedling buddings and nutrient uptake between scion and rootstock.
\end{abstract}

Keywords-Hevea brasiliensis, Mini-seedling budding, Reverse bud-grafting, Growth, Nutrient uptake.

\section{INTRODUCTION}

The tropical tree Hevea brasiliensis is commercially grown for its latex, but its trunk is tall, fragile and prone to wind damage. Wind damage is the main disaster in Hainan Province rubber planting area, and the main cause affecting the output per unit area of rubber. Typhoons occur frequently in Hainan Province, and the hazard covers the whole province, causing serious losses every year. In areas frequently hit by strong typhoons, the cumulative fall rate of tapping trees is generally $20 \%$ to $40 \%$, and more than $80 \%$ in some severe areas. To reduce the loss of wind damage, various methods were used, such as planting wind resistance clones[1], topping at 2.2- $2.5 \mathrm{~m}$ after field transplanting[2], grafting three-part rubber trees[3], transferring dwarf gene into Hevea brasiliensis [4, 5] and budding reverse[6]. However, wind resistance clones are limited in frequency and intensity of typhoons, topping effects are diminishing with time[2], three-part grafting trees are facing latex yield loss[3], dwarf gene transgenic plants are still investigating and reverse budding of rubber tree is recorded for dwarf but no detailed literature. Inverse grafting weakened the growth of chestnut, and tissue segregation showed that length and diameter of callus vessel were shorter than that of cis grafting, and the endwall inclination was increased, and the type of vessel with tail was larger [7]. However, Inverse grafting of grape sapling exhibited better growth, faster fruit to bear and better fruit [8].

Mini-seedling budding of Hevea brasiliensis is the main planting material for rubber saplings in China, which is budded 2-3 weeks after sowing and raised up to 2-3 leaf whorls in 4-6 months, can reduce the nursery time by 3 12 months for raising polybag buddings compared with the traditional method for raising budded stumps, resulting in lower cost and less labour intensity as well as higher productivity of the nursery per unit area[9]. 
For the research reported herein, we investigated the effects of reverse bud-grafting on growth and nutrient uptake of rubber mini-seedling buddings and further understand reverse budding of Hevea brasiliensis.

\section{MATERIAL AND METHODS}

The experiment was conducted from April 2017 to March 2020 in the protective cultivation base of natural rubber of Rubber Research Institute of Chinese Academy of Tropical Agricultural Sciences, Danzhou City, Hainan Province, China. Clone GT1 seeds were sown in nursery trays (32 holes, $6 \mathrm{~cm}$ top diameter* $11.5 \mathrm{~cm}$ depth $* 2 \mathrm{~cm}$ bottom diameter) and 15-20 days later the GT1 seedlings as rootstock were budded with scion CATAS 7-33-97 at reverse and cis direction, respectively. After budding successfully, they are raised in root-container with pure coconut bran. Other nursery of mini-seedling buddings was according to the conventional practices [10]. At nursery stage of 4 leaf whorls, leaf whorls and rootstock-scion angle were measured (three replications, each replication contain 30 plants), and then part of buddings were transplanted to the field. At field stage, the buddings (three replications, each replication contain 20 plants) diameter at $1 \mathrm{~m}$ above ground were measured at 3 and 18 months after transplanting. Meanwhile, at nursery stage of 10 leaf whorls (three replication, each replication contain 8 plants), the diameter of scion shoot, rootstock-scion combination and rootstock at the same height of $5 \mathrm{~cm}$ above rootstockscion combination were recorded, and then each part of scion shoot, rootstock-scion combination and rootstock were grinded into powder for nutrient determination, respectively. Sugar content were measured according to $\mathrm{Li}$ [11]. Mineral elements content was determined according to Bao [12]. Statistical analyses were performed with Data Processing System (DPS) statistical software package version 16.5 (Tang, 2013) using Student's t-test.

\section{RESULT AND DISCUSSION}

\section{Effect of reverse bud-grafting on leaf whorls}

As shown in Figure2A, at nursery stage the leaf whorls of reverse bud-grafting were $16.37 \%$ more $(p=0.0403)$ than that of cis bud-grafting. As we observed, plant height of reverse and cis bud-grafting had no significant difference(data not shown), but reverse bud-grafting had one more leaf whorl, which showed that reverse budgrafting affected the elongation between leaf whorls and caused buddings dwarf[6]. The dwarf effect of reverse bud-grafting is like transgenic plant [4] that shortened space between leaf whorls in rubber tree.
Effect of reverse bud-grafting on rootstock-scion angle As shown in Figure2B, at nursery stage the rootstock-scion angle of reverse bud-grafting was $66.66 \%$ more $(p=0.0000)$ than that of cis bud-grafting. Rootstock-scion angle was highly related with developmental stage and genetic relationship of scions [13], which indicated the smaller the angle, the better the affinity. While inverted grafting of Yan Shan Chestnut has the advantages of easy operation, high grafting efficiency, large angle of branches spreading, moderated growth, illumination improvement, reduced the tree canopy, lower height, convenient management[14], which is suitable for high density orchard renovation of chestnut. Therefore, reverse grafting had rootstock-scion angle large(Figure1) and the effects of large angle in rubber tree should be observed further in the field.

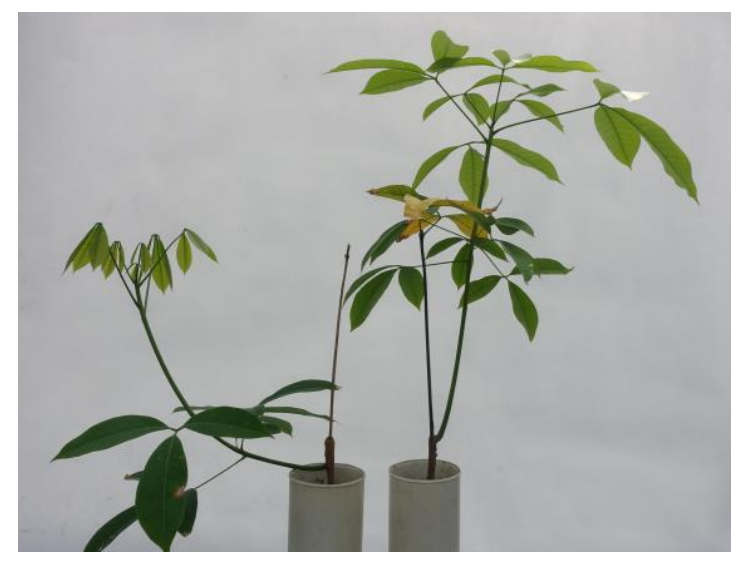

Fig. 1 Mini-seedling budding of 2 leaf whorls

Left, reverse bud-grafting, right, cis bud-grafting.

Effect of reverse bud-grafting on diameter at nursery stage As shown in Figure2D, the diameter of reverse budgrafting was $23.57 \%$ more $(\mathrm{p}=0.0052)$ in rootstock, $18.31 \%$ more $(\mathrm{p}=0.0301)$ in rootstock-scion, and $18.31 \%$ more $(\mathrm{p}=0.0447)$ in scion than those of cis bud-grafting, respectively. The results showed that reverse bud-grafting of mini-seedling buddings had a strengthening growth at nursery stage.

Effect of reverse bud-grafting on diameter at field stage As shown in Figure2C, the diameter of reverse budgrafting was $23.25 \%$ less $(\mathrm{p}=0.0000)$ at 3 months, and $11.65 \%$ less $(p=0.0000)$ at 18 months, than those of cis bud-grafting, respectively. The results showed that reverse bud-grafting of mini-seedling buddings had a weaken growth at $1 \mathrm{~m}$ above the ground at field stage.

Effect of reverse bud-grafting on nutrient uptake As shown in Table 1, for scion shoot, the content of reverse bud-grafting was $34.19 \%$ less $(\mathrm{p}<0.001)$ in $\mathrm{N}, 16.12 \%$ less $(\mathrm{p}<0.01)$ in $\mathrm{P}$, and $37.63 \%$ more $(\mathrm{p}<0.01)$ in $\mathrm{C} / \mathrm{N}$ than 
those of cis bud-grafting, respectively. For rootstock-scion combination, the content of reverse bud-grafting was $10.76 \%$ less $(p<0.01)$ in $N, 14.05 \%$ less $(p<0.05)$ in $P$, $19.92 \%$ more $(p<0.01)$ in $K, 30.03 \%$ more $(p<0.001)$ in soluble sugar, and $45.94 \%$ more $(\mathrm{p}<0.001)$ in $\mathrm{C} / \mathrm{N}$ than

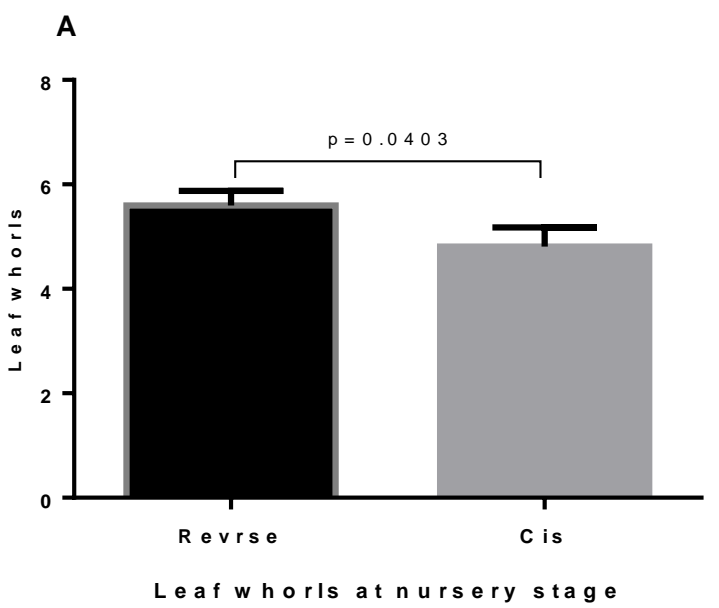

C

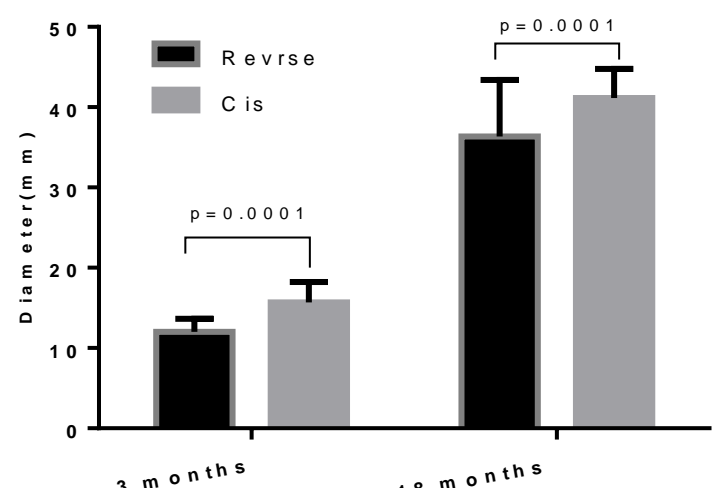

Growth of $m$ in i-seedling budding at field stage those of cis bud-grafting, respectively. For rootstock, the content of reverse bud-grafting was $39.65 \%$ less $(\mathrm{p}<0.001)$ in $\mathrm{N}, 38.11 \%$ less $(\mathrm{p}<0.001)$ in $\mathrm{P}, 5.65 \%$ less $(\mathrm{p}<0.05)$ in $\mathrm{K}$, and $67.31 \%$ more $(\mathrm{p}<0.001)$ in $\mathrm{C} / \mathrm{N}$ than those of cis budgrafting, respectively.
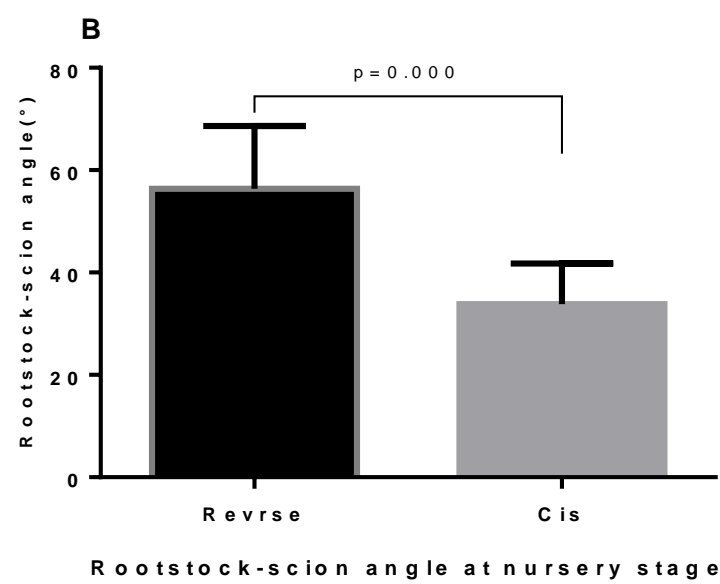

$$
\text { D }
$$

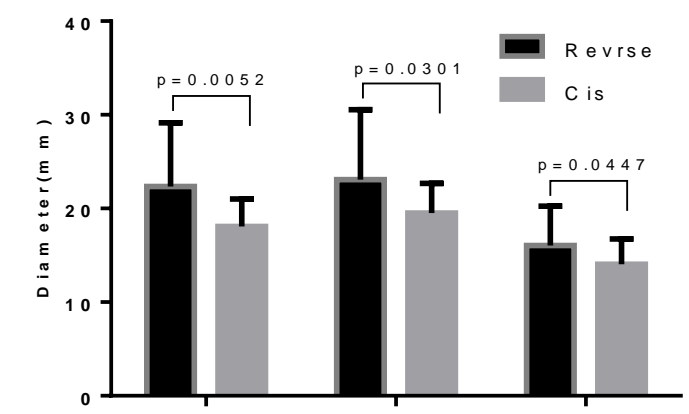

roots to ck

scion

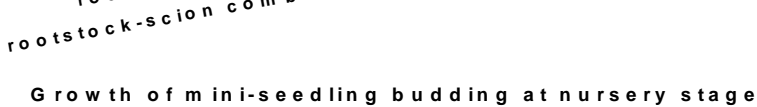

Fig.2 Effect of reverse bud-grafting on growth of mini-seedling buddings at leaf whorls (A), rootstock-scion angle (B), diameter of nursery stage $(D)$ and diameter of field stage $(C)$. Data are means and $\mathrm{SD}, \mathrm{n}=3$.

Table 1. Effect of reverse bud-grafting on nutrient uptake of mini-seedling buddings

\begin{tabular}{|c|c|c|c|c|c|c|}
\hline position & $\begin{array}{l}\text { grafting } \\
\text { direction }\end{array}$ & $\mathrm{N} \%$ & $\mathrm{P} \%$ & $\mathrm{~K} \%$ & $\begin{array}{c}\text { soluble sugar } \\
\mathrm{mg} / \mathrm{g})\end{array}$ & $\mathrm{C} / \mathrm{N}$ \\
\hline \multirow[t]{2}{*}{ Scion shoot } & Reverse & $0.55 \pm 0.01$ & $0.21 \pm 0.01$ & $0.48 \pm 0.04$ & $11.42 \pm 0.67$ & $20.84 \pm 1.7 * *$ \\
\hline & Cis & $0.84 \pm 0.03 * * *$ & $0.25 \pm 0.01 * *$ & $0.5 \pm 0.02$ & $12.62 \pm 1.02$ & $15.14 \pm 1.75$ \\
\hline \multirow{2}{*}{$\begin{array}{l}\text { Rootstock-scion } \\
\text { combination }\end{array}$} & Reverse & $0.67 \pm 0$ & $0.19 \pm 0.01$ & $0.6 \pm 0.03 * *$ & $17.9 \pm 0.48 * *$ & $26.54 \pm 0.85^{* * *}$ \\
\hline & Cis & $0.76 \pm 0.02 * *$ & $0.22 \pm 0.02 *$ & $0.5 \pm 0.04$ & $13.77 \pm 1.51$ & $18.18 \pm 1.73$ \\
\hline \multirow[t]{2}{*}{ Rootstock } & Reverse & $0.55 \pm 0.01$ & $0.12 \pm 0.01$ & $0.64 \pm 0.02$ & $12.68 \pm 0.66$ & $23.09 \pm 1.66 * * *$ \\
\hline & Cis & $0.91 \pm 0.01 * * *$ & $0.19 \pm 0 * * *$ & $0.68 \pm 0.02 *$ & $12.57 \pm 1.34$ & $13.8 \pm 1.55$ \\
\hline
\end{tabular}

Note: Data are means and SD, $=3 . *, * * * * *$ indicate a significant difference at $0.05,0.01$ and 0.001 levels, respectively. 
Nitrogen $(\mathrm{N})$ is an essential nutrient for the growth of rubber trees. The abundance and deficiency of nitrogen is closely related to the chlorophyll content in leaves, which affects the photosynthesis and growth of rubber trees. Phosphorus (P) deficiency can inhibit the growth of rubber trees. In this study, reverse bud-grafting caused the accumulation of $\mathrm{N}$ and $\mathrm{P}$ decreased in scion shoot, rootstock-scion combination and rootstock, which had one more leaf whorl and accordingly shortened the space between leaf whorls at the same nursery level. Potassium $(\mathrm{K})$ is to directly affect the metabolism of rubber trees, such as promoting photosynthesis and improving the absorption and utilization of nitrogen. Soluble sugar content in plants can be an indicator of the level of carbon metabolism, which influence latex yield [15]. In this study, reverse bud-grafting made rootstock-scion combination diameter bigger, more $\mathrm{K}$ and more soluble sugar accumulation, which slowed down the nutrient communication between rootstock and scion, and shortened space between leaf whorls. $\mathrm{C} / \mathrm{N}$ ratio reflects the growth stage of plants. Plants need more nitrogen at the growing period, while the carbohydrate produced by photosynthesis at the mature or near mature period keeps accumulating, and the carbon is also increasing. In this study, reverse bud-grafting had scion, rootstock-scion combination and rootstock bigger $\mathrm{C} / \mathrm{N}$ ratio, respectively, which caused by lower $\mathrm{N}$ level and one more leaf whorl accordingly.

\section{CONCLUSION}

In summary, reverse bud-grafting of rubber mini-seedling buddings had more leaf whorls, short space between leaf whorls, large angle between rootstock-scion, and bigger diameter near rootstock-scion combination at nursery stage, but at field stage smaller diameter of $1 \mathrm{~m}$ above ground. There may be two main reasons for the changes. One was bigger diameter of rootstock-scion combination caused by reverse bud-grafting, which affected nutrient uptake. The other might be insufficient fertilizer and water supply at field stage.

\section{ACKNOWLEDGEMENTS}

This work was supported by the earmarked fund for China Agriculture Research System (CARS-34-YZ4).

\section{REFERENCES}

[1] Lin W (2007) Discussion on the Improvement of cultivation measures for wind damage reduction in rubber trees. Chinese Journal of Tropical agriculture, (3):7-9.
[2] Xie G, Huang Y (2007) Young rubber tree topping does more harm than good. Chinese Journal of Tropical agriculture, (6):19-20.

[3] Lin W, Huang S (1995) Dwarf three-part tress of Hevea brasiliensis. Chinese Journal of Tropical Crops, 16 (1):1-9.

[4] Zhou Q, Li J, Sun A, Hua Y, Huang H (2016) T-DNA insertion site of dwarf mutant in Heava brasiliensis transferred of $\mathrm{HbCBFl}$ gene. Chinese Journal of Tropical Crops 37 (10):1931-1937.

[5] Lei H, Wang Y, Chen X, Zhang X (2010) Studies on GAI transgenic plants of Hevea brasiliensis by particle bombardment. Journal of Tropical and Subtropical Botany, 18 (2):165-169.

[6] Huang H (2005) Fifty years of rubber tree breeding in China. China agricultural press, Beijing, pp 66.

[7] Ji L, Zhang J, Wang T, Qi Y (2016) Effects of inverted graft on molecular characteristics of callus vessel in Chestnut (Castanea mollissima Blume). Journal of Hebei Normal University of Science and Technology, 30 (4):2932.

[8] Cai Y, Qin Z, Zhao F, Wang F, Guo J, Ma H (2016) A method of grape reverse grafting, pp 4.

[9] Huang S (1988) Mini-seedling rootstock budding technology research bulletin. Tropical Crops Research, (2):60.

[10] Huang S (1989) A new method of rubber asexual propagation - Mini-seedling budding of Hevea brasiliensis. Chinese Journal of Tropical crops (01):25-31.

[11] $\mathrm{Li} \mathrm{H}$ (2000) Principles and techniques of plant physiological biochemical experiment. Higher Education Press, Beijing, pp 195-197.

[12] Bao S (2008) Soil and agricultural chemistry analysis. Agriculture Press of China, Beijing, pp 264-279.

[13] Chen X, Wang J, Lin W, Chen Q (2015) Affinity of five scions budded on clonal rootstocks Reyan7-33-97. Chinese Journal of Tropical Agriculture, (7):1-4.

[14] Zhang J, Cao F, Ji L, Wang C, Qi Y, Wang T (2018) Inverted grafting technology of Yanshan Chestnut. Northern Horticulture, (8):197-199.

[15] Lima DUD, Oliveira LEMD, Soares AM, DelúFilho N (2002) Seasonal evaluation of latex yield and soluble sugar dynamics in rubber trees (Hevea brasiliensis müll. arg.) cultivated in Lavras, MG. revista árvore, 26 (3):377-383. 